\title{
ENVIRONMENTAL MANAGEMENT SYSTEMS IN HIGHER EDUCATION INSTITUTIONS, BEYOND REGULATIONS
}

\author{
Cristina Mihaela SALCĂ ROTARU ${ }^{1}$
}

\begin{abstract}
Environmental management systems are usually associated with industry, considered to be the major polluters of the environment. This article presents the need to implement such a system in higher education institutions, starting from its regulations and demonstrating the possible similarity of universities with a large economic entity. Some examples of good practice are also presented. The conclusions present the importance of the role of the academic community and the opportunity to integrate an environmental management system with the other specific management systems, existing at the level of universities.
\end{abstract}

Key words: environmental management system, higher education institutions, environmental law, environmental standards

\section{Introduction}

Environmental management systems (EMS) are an instrument of voluntary environmental commitment and an important legal instrument regarding environmental protection in the European Union (Salcă Rotaru, 2019, p.193). The voluntary nature of EMS makes its implementation stronger in the industrial fields and almost absent in the public administration and education sectors. This difference can be explained in terms of economic interests that differ between areas. If the industrial economic sector is already largely adopting the implementation of an EMS, in the education sector, even at the level of higher education institutions (HEI), there is a timid one-off approach.

This article, based on EMS rules, draws a parallel between $\mathrm{HEI}$ and an enterprise in terms of their economic and personnel size looks for differences that can lead to the implementation of an EMS, and shows good practices encountered in the specialized literature or implemented in $\mathrm{HEl}$.

\section{A brief look at the regulations}

The first EMS was introduced at the level of the European Union, through Regulation

\footnotetext{
${ }^{1}$ Transilvania University of Braşov, Law Faculty, rotaruc@unitbv.ro.
} 
no. 1836 of 1993 to allow the voluntary participation of companies in the industrial sector in a community system of ecological management and audit. This regulation was the effect, the result of European Community action policies (EAP), which for the period 1993-1997, in the fifth EAP entitled "Towards Sustainability" concluded that it is necessary to introduce legislation environmental standards (EAP 5, 1993, p.76).

Thus, the first EMS was conceived as a proactive approach to the environmental responsibility of organizations in the industrial environment, which requires companies "to establish and implement policies, objectives and environmental programs and effective environmental management systems." (Council Regulation, 1993, p.1)

The positive experience of the implementation of this system determined in 2001 its generalization to any organization with an impact on the environment, thus providing "a means for them to manage these impacts and improve their overall environmental performance" (Regulation, 2001, p.2). The novelty is that "in addition to the general requirements of the environmental management system EMAS places special significance on the following elements: legal compliance, improvement of environmental performance and also external communication and employee involvement."(Regulation, 2001, p.2)

In 1996, the International Organization for Standardization (ISO) launched the environmental standards class 14000. In 1997, it was recognized that the two standards, EMAS and ISO 14000 "contain similar requirements" (Commission Decision, 1997, p.37), becoming the most important at European and international level.

The evolution of the two standards has determined their mutual adaptation along the way, highlighted especially at the level of EMAS, given that it is based on a normative act. In this regard we mention: (i) Commission Regulation No 196/2006 amending Annex I to Regulation No 761/2001 to take account of the European Standard EN ISO 14001:2004 and (ii) Regulation No 1221/2009 on the voluntary participation by organisations in a Community eco-management and audit scheme (EMAS). The international opening of EMAS is enshrined in a decision on the registration of third parties country organizations and global registration (Commission Decision, 2011, p.25).

\section{EMS in higher education institutions}

\subsection{National aspects}

At national level, there are no practical concerns regarding the implementation of an environmental management system in higher education institutions. This statement is supported by research conducted on the websites of these institutions, which contain only information on the existence of a quality management system, and does not contain information on the possible integration of the environmental management system.

And at the level of theoretical studies, the research carried out is reduced. There is a research in this regard (Dabija, 2017, p.533) that tries to assess the perception that different groups of stakeholders have on one of the largest and most important universities in Romania in terms of its orientation in the field of sustainable 
development, including the environmental component. The paper offers a new approach to how a university can and should focus on the various specific sustainability measures in order to achieve a better position in the education market. It is emphasized that the university sets social trends and that the study of sustainability in a university could be seen as a novel approach.

There are also some punctual, but minor approaches, in terms of environmental protection, through actions or projects of students, but without having an institutional integration.

For a broader approach we can mention a project at regional level (Project, 2014, p.103) which used as a tool "Eco-Mapping", considered as a flexible, independent means for eco-conscious management in order to introduce EMAS and ISO 14001, in a demonstrative variant. The case studies of the project included Eco-mapping of Sapientia University, but only considered the aspects related to energy, water and noise.

\subsection{Discussions on the motivations for implementing an EMS}

A study on the costs and benefits (Study, 2009, p.i) that involves the implementation of an environmental management system on both private and public entities highlighted, in the alternative, their motivation for implementing such a system.

Research on public and private sector reasons for adopting EMAS (Study, 2009, p.vi) shows that:

- "Improved reputation" has a lower level of importance at the level of public institutions (4\%) than at private entities (15\%);

- "Legislative compliance" has a lower level of importance at the level of private entities (9\%) than public institutions (11\%);

- "Employee participation" has a lower level of importance at the level of private entities (4\%) than public institutions (10\%);

The same study showed that, taking into account the field of activity sectors, in the field of health, education, social services, the number of organization with EMS was much lower than other sectors.

This lack of interest can also be motivated by the lack of a economic concern regarding the existence, implementation of an EMS.

What is little known, or aware, is that HEl is a public entity whose size, applying the rules for assessing the classification of a company in small, medium / medium or large (Commission Recommendation, 2003, p.39), is impressive and comparable to a large company (entities with more than 250 employees and an annual turnover and / or total annual balance sheet exceeding EUR 43 million).

We can exemplify with the Transilvania University of Brașov, which:

- has approx. 1200 employees, 735 of them being tenured teachers (Figure 1) 


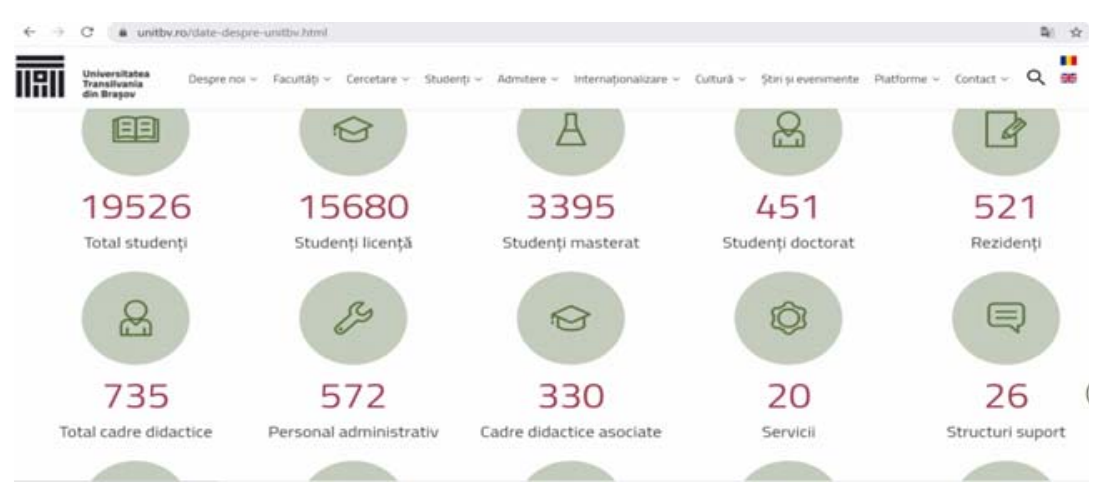

Fig. 1. Number of employees, source: www.unitbv.ro, accessed June 30, 2020

- the operational revenues, according to the annual balance sheets of the institution are: 64,112,979 euro / 2019 (Balance sheet, 2019, p.2), 46,919,366 euro / 2018 (Balance sheet, 2018, p.2), 43,308,000 euro / 2017 (Balance Sheet, 2017, p.2)

Corroborating this information, we can say that the Transilvania University of Brașov can be compared to a large private enterprise.

Given the fact that most higher education institutions fall into this category, there is also the importance of implementing an environmental management system within them.

\subsection{International issue}

Some EU countries, and not only, have already established at national level models of good practice on environmental protection in the form of environmental management systems for higher education institutions. Among these I would mention: (i) Osnabrück University model, Germany (Vieban, 2002, p.3); (ii) Auditing Instruments for Sustainability in Higher Education - AISHE, Netherlands (Roorda, 2001); (iii) Sustainable University model, Mexico (Velazquez, 2006, p.810); (iv) Environmental Management Guide for Colleges and Universities (EPAA, 2007); (v) The model implemented in Swedish universities (Sammalisto, 2005, p. 18).

Starting from the costs of implementing an EMS, I consider that the environmental management model for the Swedish university, Osnabrück is perfectly applicable to universities with a mixed profile (engineering sciences, social sciences) as is the Transilvania University of Brașov. This model contains ten "building blocks" that are developed by the departments considered most competent to design and operate them, without resorting to external consultants or an individual manager.

For example, the IT faculty / department would develop an "Environmental Information System", the faculty / public relations / communication department would write an environmental report and the law faculty / department would create a register of relevant legislation and regulations, and others. The advantage is that an existing, specialized structure is used and can also be a basis for more intense collaboration between departments / faculties. 
There are also models developed individually by higher education institutions. A model that can be considered when developing an environmental management system for higher education institutions in Romania is that of Cambridge University, UK, which has implemented the Cambridge Green Challenge program (https://www.environment.admin.cam .ac.uk /), based on the SMM for ISO-14000. This program takes into account the fact that every aspect of the University's activity has an impact on the environment and that every person who works or studies at the University has a role in taking measures to reduce the impact on the environment during their time at Cambridge.

The system was implemented in 2015 and, starting with 2016, the Annual Report is made public, which provides details about the University's successes, lessons learned and plans for next year. Areas of action are: energy, waste and recycling, water, biodiversity and ecosystems, travel, green public procurement, buildings and land.

Schematically, the vision, policy and structure of the system on environmental protection are presented by the University (Environmental Sustainability, Vision, Policy Framework, 2015, p.4), in Figure 2 Policy Framework:

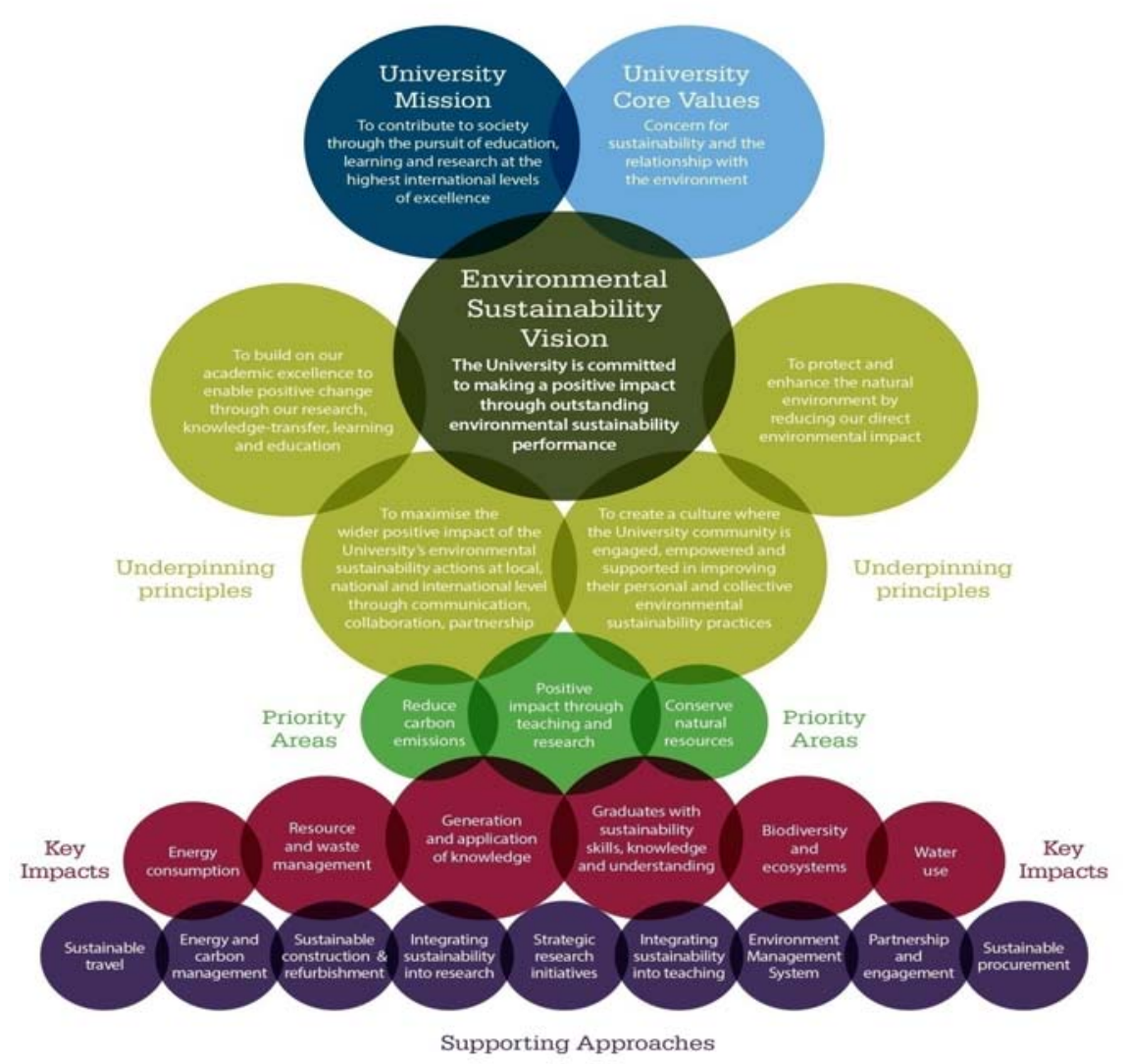

Fig. 2. Policy Framework

Source: Environmental Sustainability, Vision, Policy Framework, 2015, p.4 
It is clear that the development of such a complex system requires an initial environmental impact assessment of the institution, i.e. an in-depth environmental analysis, taking into account all activities, direct and indirect impacts, costs and revenues or benefits from the implementation and compliance with this system.

The challenge posed by sustainability requirements requires a clearer establishment of accountability at all institutional and social levels, an accountability that cannot take place without taking into account new styles of institutional organization.

The start of an international collaboration of $8 \mathrm{HEls}$ (Australian National University; University of California, Berkeley; University of Cambridge; Imperial College London; London School of Economics and Political Science; Massachusetts Institute of Technology; University of Tokyo, and Tsinghua University) which establishes the Global Alliance of Universities on Climate (GAUC). GAUC is intended as a mechanism for exchange and cooperation, specifically to lead efforts from global higher education to examine the technical, social, psychological, institutional and economic issues of climate change and how practical action can be implemented (GAUC, 2019).

Referring to higher education institutions, this involves both strengthening and supporting interdisciplinary research, as well as a stronger awareness of community members, by involving them in setting institutional priorities. No system, however wellstructured, can be truly implemented and bring real environmental benefits if it is not assumed by every member of the academic community.

It should be mentioned that in order to develop such guides, environmental management systems require the existence of a central vision and a real concern for environmental protection.

Also, the environmental management system must be integrated and harmonized with the other management systems, starting with the educational one, the quality management one, the risk management and the health and safety at work.

\section{Conclusions}

Even if the object of activity, education, seems to be one that is not related to the highly polluting economic fields, the academic community must be aware of the impact of an $\mathrm{HEl}$ on the environment, as it results from its comparison with a large enterprise.

Higher education institutions play a major role in preparing future generations for a sustainable society, forming skills and competences, both through the curriculum and by establishing environmental rules of conduct at their level.

The involvement of the academic community is not only aimed at students but also teachers and administrative staff, and it is necessary to develop environmental skills and abilities at their level.

The simplest way to impose these rules is to implement an EMS that can be easily integrated through other existing management systems at a university level. 


\section{References}

Bilanț. (2019). [Balance sheet]. p.2. https://www.unitbv.ro/despre-unitbv/informatii-deinteres-public/transparenta-institutionala/buget-bilanturi-contabile.html

Bilanț. (2018). [Balance sheet]. p.2, https://www.unitbv.ro/despre-unitbv/informatii-deinteres-public/transparenta-institutionala/buget-bilanturi-contabile.html

Bilanț. (2017). [Balance sheet]. p.2, https://www.unitbv.ro/despre-unitbv/informatii-deinteres-public/transparenta-institutionala/buget-bilanturi-contabile.html

Cambridge Green Challenge program (2015). available at: https://www.environment.admin.cam.ac.uk/

Commission Decision 97/265/EC: of 16 April 1997 on the recognition of the international standard ISO 14001:1996 and the European standard EN ISO 14001:1996, establishing specification for environmental management systems, in accordance with Article 12 of Council Regulation (EEC) No 1836/93 of 29 June 1993, allowing voluntary participation by companies in the industrial sector in a Community eco-management and audit scheme. (1997). JO L 104, 22.4.1997, pp. 37-38

Commission Recommendation of 6 May 2003 concerning the definition of micro, small and medium-sized enterprises. (2003). OJ L 124, 20.5.2003, p. 36-41

Commission Decision 2011/832/EU concerning a guide on EU corporate registration, third country and global registration under Regulation (EC) No 1221/2009 of the European Parliament and of the Council on the voluntary participation by organisations in a Community eco-management and audit scheme (EMAS). (2011). JO L 330, 14.12.2011, p. 25-38

Council Regulation No 1836/93 of 29 June 1993, allowing voluntary participation by companies in the industrial sector in a Community eco-management and audit scheme. (1993). JO L 168, 10.7.1993, p. 1-18

Dabija, D.C., Postelnicu, C., Dinu V., Mihăilă A. (2017). Stakeholders' perception of sustainability orientation within a major Romanian University. International Journal of Sustainability in Higher Education, International Journal of Sustainability in Higher Education, vol. 18, no. 4, pp. 533-553. https://doi.org/10.1108/IJSHE-10-2015-0169

Environmental Sustainability, Vision, Policy Framework. (2015) p.4. available at: https://www.environment.admin.cam.ac.uk/files/environmental_sustainability_vision _policy_and_strategy_for_web.pdf

Joint Statement on the Co-Founding of Global Alliance of Universities on Climate (GAUC) https://news.tsinghua.edu.cn/en/info/1002/7940.htm

Proiect "Un mediu mai curat cu costuri reduse". (2014). [Project "A cleaner environment with low costs"] available at:

https://natura2000.ro/wpcontent/uploads/2014/10/Publication.Ghid.management.mediu.pdf

Regulation (EC) No 761/2001 of the European Parliament and of the Council of 19 March 2001 allowing voluntary participation by organisations in a Community ecomanagement and audit scheme (EMAS). (2001). JO L 114, 24.4.2001, p. 1-29

Roorda, N. (2001). Auditing instrument for sustainability in higher education. Holland: Dutch Committee on Sustainable Higher Education. 
(https://niko.roorda.nu/books/aishe/

Salcă Rotaru, C.M. (2019). The Environmental Management System between freedom of will and legal impose, Union of Jurists of Romania. Law Review; Bucharest Vol. X, Iss. 2, (Jul-Dec 2019), pp.192-201

Sammalisto, K., Ardvidsson, K. (2005). Environmental management in Swedish higher education. Directives, driving forces, hindrances, environmental aspects and environmental co-coordinators in Swedish universities. International journal of sustainability in higher education, Vol. 6 No. 1, pp. 18-35, DOI: $10.1108 / 14676370510573113$

Study on the Costs and Benefits of EMAS to Registered Organisations, Study Contract No. 07.0307/2008/517800/ETU/G.2. (2009). p.vi, available at: https://ec.europa.eu/environment/emas/pdf/other/costs_and_benefits_of_emas.pdf

Towards Sustainability - a European Community programme of policy and action in relation to the environment and sustainable development (EAP 5). (1993) https://ec.europa.eu/environment/archives/action-programme/envact5/pdf/5eap.pdf

U.S. Environmental Protection Agency Auditing (EPAA), Office of Environmental Stewardship, October 2007, available at: https://archive.epa.gov/region03/green/web/pdf/ems-guide-4-college-university07.pdf

Velazquez, L, Munguia, N, Platt A, Taddei J. (2006). Sustainable university: what can be the matter? Journal for Cleaner Production, 14 pp.810-819. DOI: 10.1016/j.jclepro.2005.12.008

Viebahn, P. (2002). An environmental management model for universities: from environmental guidelines to staff involvement. (2002). Journal of Cleaner Production, 10: pp.3-12. DOI: 10.1016/S0959-6526(01)00017-8 